Article

\title{
Synthesis, Performance and Emission Quality Assessment of Ecodiesel from Castor Oil in Diesel/Biofuel/Alcohol Triple Blends in a Diesel Engine
}

\author{
Beatriz Hurtado ${ }^{1}$, Alejandro Posadillo ${ }^{2}$, Diego Luna ${ }^{1, * \mathbb{C}}$, Felipa M. Bautista ${ }^{1}$,

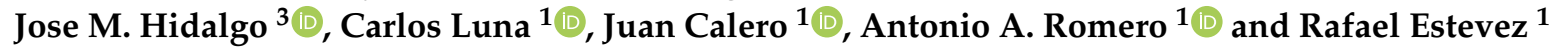 \\ 1 Departamento de Química Orgánica, Universidad de Córdoba, Campus de Rabanales, Ed. Marie Curie, \\ 14014 Córdoba, Spain; q02huceb@uco.es (B.H.); qo1baruf@uco.es (F.M.B.); qo2luduc@uco.es (C.L.); \\ p72camaj@gmail.com (J.C.); qo1rorea@uco.es (A.A.R.); rafa_20_15@hotmail.com (R.E.) \\ 2 Seneca Green Catalyst S.L., Campus de Rabanales, 14014 Córdoba, Spain; seneca@uco.es \\ 3 Institute of Physical Chemistry, Polish Academy of Sciences, ul. Kasprzaka 44/52, 01-224 Warsaw, Poland; \\ jose.hidalgo@unicre.cz \\ * Correspondence: diego.luna@uco.es; Tel.: +34-957212065
}

Received: 13 November 2018; Accepted: 20 December 2018; Published: 3 January 2019

check for updates

\begin{abstract}
This research aims to promote the use of second-generation biofuels based mainly on Castor oil, which is not adequate for food use, and Sunflower oil as a standard reference for recycled oils. They have been applied in the production of Ecodiesel, a biofuel that integrates glycerol as monoglyceride, employing sodium methoxide as homogeneous catalyst and ethanol as solvent, but operating in milder conditions than in the synthesis of conventional biodiesel in order to obtain a kinetic control of the selective transesterification. The behavior of biofuels has been evaluated in a conventional diesel engine, operating as an electricity generator. The contamination degree was also evaluated from the opacity values of the generated smokes. The different biofuels here studied have practically no differences in the behavior with respect to the power generated, although a small increase in the fuel consumption was obtained in some cases. However, with the biofuels employed, a significant reduction, up to $40 \%$, in the emission of pollutants is obtained, mainly with the blend diesel/castor oil/alcohol. Besides, it is found that pure Castor oil can be employed directly as biofuel in triple blends diesel/biofuel/alcohol, exhibiting results that are very close to those obtained using biodiesel or Ecodiesel.
\end{abstract}

Keywords: castor oil; biofuel; selective transesterification; ecodiesel; biodiesel; diesel engine; electricity generator; smoke opacity; Bacharach opacity

\section{Introduction}

Nowadays, regardless of the introduction of vehicles that incorporate electric or hydrogen engines, the gradual incorporation of biofuels as substitute of fossil fuels is still mandatory [1]. The use of biofuels palliate the depletion of fossil fuels, minimize the negative impact of greenhouse gases, producing less amount of carbon monoxide, sulfur dioxide and unburned hydrocarbons than fossil fuel [2,3], and also allow continued use of the fleet of cars currently existing, estimated at more than a billion, without modifying the compression ignition (C.I.) engines [4]. Furthermore, biofuels and, specifically the biodiesel, can be easily integrated into the logistic of the global transportation system $[5,6]$. The gradual replacement of fossil fuels by others of renewable nature involves the introduction of blends diesel/biofuel. In this sense, the objectives pursued by the EU are estimated at 
$20 \%$ of biofuel in the blend in 2020 and $30 \%$ in 2030. Despite these objectives are apparently not difficult to achieve, the enormous amount of glycerol produced during the synthesis of biodiesel makes that other approaches can be considered in order to accomplish the fossil replacement to a higher extent. In this respect, a viable option could be the use of unprocessed vegetable oils in double blends with conventional diesel. This is theoretically possible because all the relevant physicochemical properties, for its use as fuels in conventional diesel engines, are comparable to conventional diesel, with the exception of the viscosity, much higher in oils than in diesel [7]. Another approach is related to the use of alcohols in triple blends with diesel and different biofuels. According to EN 14214, the presence of alcohols in fuel and biofuels does not constitute any inconvenience. In fact, according to recent research, the presence of ethanol and other short-chain alcohols has a favorable effect on the emissions of the biofuels [8-11], so it is advisable the addition of certain quantities of ethanol to the diesel No. 2 standard. These mixtures constitute the so-called E diesel, oxidiesel or oxygenated diesel, which apart from reducing the emissions of the C.I. engines, improves the flow properties (viscosity) and the essential parameters that limit the application of diesel when operating at low temperatures [12], like the "cloud point" (CP), "pour point" (PP), cold filter plugging point temperature (CFPP), or point of occlusion of the cold filter (POFF), viscosity, and emission levels of the motors, without any significant negative effect in most of the parameters that define the quality of biodiesel [13-16]. Thus, the use of alcohols in triple mixtures diesel/biofuel/alcohol would allow to replace larger amounts of fossil diesel than those achieved using double diesel/biofuel blends. In fact, the utility of the triple diesel/biodiesel/ethanol blends has been patented under the name of Diesterol $[17,18]$. These blends reduce emissions, viscosity and flash point, together to a slight reduction of the engine power [13-18].

Considering the biofuel synthesis and taking into account the available technology, the conventional biodiesel production described by the standard EN 14214, present as the main drawback the glycerol generated as byproduct, which is a $10 \%$ by weight of the total of biodiesel produced [19]. For instance, the Lurgi's biodiesel fabrication technology is based on two successive transesterification reactions of TG with methanol to form FAME and glycerol in the presence of an alkaline catalyst [20]. At the end of the reaction, the mixture is neutralized by adding hydrochloric acid. A subsequent counter-current washing step removes by-product components and gives a "ready for use" biodiesel after final drying step. The washing step of biodiesel to eliminate glycerol residues, that must be less than $0.02 \%$, provides an additional complication. On one hand, it requires processing with high energy costs. On the other hand, it requires a high consumption of water. A possible solution to this problem is the production of a new type of biodiesel that integrates glycerol in the form of a soluble derivative. Thus, the production of glycerol is avoided, and, at the same time, the atomic performance of the process is increased, since all the reactive raw materials are transformed into a biofuel [21,22]. In this sense, our Research Group has accomplished the transesterification of triglycerides with ethanol to produce monoglycerides (MGs) as soluble derivatives of glycerol employing different lipases as catalysts. Hence, through the partial transesterification of one mole of triglyceride (TG) with ethanol, two moles of ethyl esters (FAEE) and one mole of monoglyceride (MG) are generated, obtaining a biofuel called Ecodiesel, Figure 1 [23-29].

However, the high cost of lipases compels to search for a more cost-effective process for producing Ecodiesel, such as the employ of supported KF or $\mathrm{CaO}$ as heterogeneous catalysts [28,29]. Thus, the Ecodiesel, constituted by the 2/1 mixture of FAME/MG can be obtained under kinetic control of the chemical process, using a catalyst less basic than the alkali metals usually employed as homogeneous catalysts in the biodiesel production. However, further attempts to reduce the economic cost of the process should be investigated. 


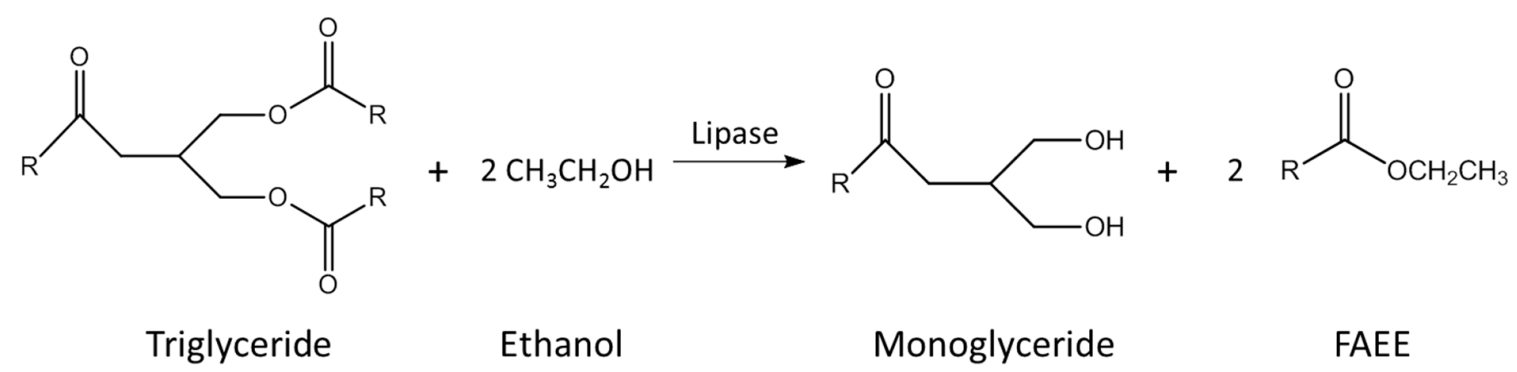

Figure 1. Selective transesterification of a triglyceride molecule through the application of enzymatic catalysis to produce Ecodiesel, a biofuel similar to biodiesel, constituted by two molecules of ethyl esters of fatty acids and a monoglyceride molecule.

In addition to the abovementioned drawback of glycerol generation during the biodiesel production, another important issue related to the biodiesel production is the ethical conflicts surrounding the production of biodiesel from edible oils, instead of using these edible oils exclusively for feeding purposes. To overcome this, the production of the so-called second-generation biofuels, which are obtained from non-edible oils and also from recycled waste oils, using procedures with minimum waste generation and high atom efficiency, are being taken into account [30,31]. Among the non-edible oils, Castor oil (Ricinus communis L.) should be a promising option because it has a large international market, since it is widely used in chemical and pharmaceutical industry [32,33] and it can be grown on marginal lands and in semi-arid climates [34]. However, it is not considered a good raw material to produce biofuels [35] because of the high kinematic viscosity that it exhibits (241.5 cSt). Likewise, the kinematic viscosity of the biodiesel obtained by its transesterification with methanol is also too high for being employed in combustion engines (15 cSt). In fact, very recent studies [36-39] have determined that Castor oil biodiesel can be only used in a 20-30\% in mixtures with fossil diesel, i.e., $\mathrm{BCO} 20$ to $\mathrm{BCO} 30$. In this respect, some researches, regarding the use of triple diesel/biodiesel/alcohol blends in order to increase the amount of biodiesel of castor oil in these blends, have been initiated [13].

Another possibility, which is barely studied at present, is that Castor oil can be employed in its pure form blending with fossil diesel [40-42]. Castor oil exhibits, in fact, advantageous rheological properties for being employed directly as biofuel, such as high solubility in very diverse organic compounds, compatibility with polar liquids of low viscosity, such as alcohols; high values of Cetane Index (81.1) and Flammability Point $\left(229^{\circ} \mathrm{C}\right)$; low cloud point -10 to $-18{ }^{\circ} \mathrm{C},\left(-23^{\circ} \mathrm{C}\right.$ in FAME), and crystallization (pour point) $-30{ }^{\circ} \mathrm{C}\left(-45^{\circ} \mathrm{C}\right.$ in FAME), which allow its use in motor oil high performance, as a lubricant and in hydraulic braking systems [34,43].

Hence, in this research, two different aspects have been addressed. On one hand, to further reduce the economic cost of the Ecodiesel production, a basic homogeneous catalytic process at the experimental conditions that are soft enough to achieve the transesterification of the esters of primary alcohols, positions 1 and 3 of glycerol, without affecting the carbon 2, a secondary alcohol, which is less reactive, has been investigated. To do so, a commercial sodium methoxide is employed as catalyst. Furthermore, in order to avoid the glycerol production that surely occurs employing methanol and an homogeneous catalyst, the possibility of using ethanol as solvent in a methanol/ethanol mixture to attenuate the higher reactivity of methanol has been studied.

On the other hand, to solve the problem of the high viscosity of Castor oil, this research deals with the possibility of increasing the amount of renewable material in biofuel blends, here so-called diesel additive, through the application of diesel/biofuel/alcohol triple blends. In this sense, the most suitable double and triple blends, according to their viscosity values, are applied as a biofuel in a conventional diesel engine, operating as an electric generator. Besides, the quality of the emissions obtained by using these biofuels was also evaluated from the opacity values of the generated smokes. 


\section{Results}

\subsection{Synthesis of Ecodiesel by Kinetic Control of the Conventional Procedure of Biodiesel Production}

As aforementioned, to obtain a selective alcoholysis of triglycerides, the use of milder conditions than those usually employed in conventional biodiesel production (FAME) is required. As can be seen in Table 1, the biodiesel production from two different oils, sunflower oil (SO) and castor oil (CO), reached a total conversion and selectivities higher than $90 \%$ to FAME + MG at $60{ }^{\circ} \mathrm{C}, 60 \mathrm{~min}$ of reaction time and employing $4 \mathrm{~mL}$ of sodium methoxide per $100 \mathrm{~mL}$ of oil. For its part, in order to substitute the lipases by a homogeneous catalyst in the Ecodiesel synthesis, the use of ethanol to reduce the glycerol production has been accomplished, due to ethanol is less reactive than methanol and can avoid the break of the ester bond of secondary alcohol). Table 2 shows the results obtained in the selective ethanolysis of Sunflower oil (SO) at room temperature $\left(25^{\circ} \mathrm{C}\right)$ and $30 \mathrm{~min}$ of reaction time, using different proportions of ethanol $(\mathrm{EtOH})$ and methanol $(\mathrm{MeOH})$.

Table 1. Results obtained in the transesterification of different oils. Reaction conditions: $100 \mathrm{~mL}$ of oil, $20 \mathrm{~mL}$ of methanol and $4 \mathrm{~mL}$ of sodium methoxide, $60^{\circ} \mathrm{C}$ and $60 \mathrm{~min}$ of reaction time. In all the cases, the conversion is $100 \%$. Sel. = FAME + MG. In the methanol fraction, $13 \mathrm{~mL}$ in this case, $2-4 \mathrm{~g}$ of glycerol and 3.5-6.5 $\mathrm{g}$ of MG were obtained.

\begin{tabular}{ccccccc}
\hline Vegetable Oil & $\begin{array}{c}\text { Oil Viscosity } \\
\text { (cSt) }\end{array}$ & $\begin{array}{c}\text { Selectivity } \\
\mathbf{( \% )}\end{array}$ & $\begin{array}{c}\text { FAME } \\
\mathbf{( \% )}\end{array}$ & $\begin{array}{c}\text { MG } \\
\mathbf{( \% )}\end{array}$ & $\begin{array}{c}\text { DG } \\
\mathbf{( \% )}\end{array}$ & $\begin{array}{c}\text { Biodiesel Viscosity } \\
\text { (cSt) }\end{array}$ \\
\hline Sunflower & 37.37 & 91.9 & 85.3 & 6.6 & 8.1 & 4 \\
Castor & 227.0 & 100 & 90.0 & 10.0 & 0.0 & 11 \\
\hline
\end{tabular}

Table 2. Results obtained in the transesterification of $500 \mathrm{~mL}$ of Sunflower oil. Reaction conditions $25{ }^{\circ} \mathrm{C}, 30 \mathrm{~min}$ of reaction time and $300 \mathrm{rpm}$. The neutralization is carried out with of $\mathrm{H}_{3} \mathrm{PO}_{4}$. No phase separation was observed.

\begin{tabular}{|c|c|c|c|c|c|c|c|c|}
\hline $\mathbf{N}^{o}$ & $\begin{array}{c}\text { EtOH } \\
(\mathrm{mL})\end{array}$ & $\begin{array}{c}\mathrm{MeOH} \\
(\mathrm{mL})\end{array}$ & $\begin{array}{c}\mathrm{NaOMe} \\
\text { (mL) }\end{array}$ & $\begin{array}{l}\text { Visc. } \\
\text { (cSt) }\end{array}$ & $\begin{array}{l}\text { Sel. } \\
(\%)\end{array}$ & $\begin{array}{l}\text { FAE } \\
(\%)\end{array}$ & $\begin{array}{l}\text { MG } \\
\text { (\%) }\end{array}$ & $\begin{array}{l}\text { DG } \\
(\%)\end{array}$ \\
\hline 1 & 25 & 35 & 10 & 6.60 & 89.1 & 64.5 & 24.6 & 10.9 \\
\hline 2 & 25 & 25 & 10 & 10.95 & 86.9 & 67.6 & 19.3 & 13.1 \\
\hline 3 & 20 & 20 & 7 & 13.18 & 80.7 & 64.3 & 15.4 & 19.3 \\
\hline 4 & 30 & 30 & 5 & 9.43 & 77.1 & 63.4 & 13.7 & 22.9 \\
\hline 5 & 25 & 25 & 5 & 13.15 & 80.0 & 64.9 & 15.1 & 20.0 \\
\hline 6 & 30 & 25 & 5 & 11.77 & 77.8 & 58.5 & 19.3 & 22.2 \\
\hline
\end{tabular}

As can be seen in Table 2, non-appreciable differences in the viscosity of the mixtures have been obtained. Furthermore, the selectivities of the reactions are between $77 \%$ and $90 \%$. Thus, we have selected the reaction conditions more favourable from an economic point of view (Entry 5), since the least amount of catalyst and alcohols are employed. This proportion can be easily transformed to a ratio if we consider the reaction of $100 \mathrm{~mL}$ of Sunflower oil. In this case, the reaction mixture would be oil/EtOH/MeOH/NaOMe ratio of 100/5/5/1.

Once the mixture of reactants was fixed, different reaction parameters such as reaction temperature (Table S1) and reaction time were also studied. Table 3 compiles the conversion values and selectivity to different products in the Ecodiesel synthesis from SO (EcoSO) and CO (EcoCO), at different reaction times, $30^{\circ} \mathrm{C}$ and with a mixture of methanol/ethanol. It is remarkable that, operating at the same experimental conditions as those employed in the Ecodiesel production over different enzymatic extracts [23-27] but with an oil/EtOH/MeOH/NaOMe ratio of 100/5/5/1, it is possible to obtain biofuels that can be mixed with fossil diesel for being employed in diesel C.I. engines, by reducing the starting viscosity of the oil in practically $1 / 3$ (Tables 1 and 3 ). Besides, an atomic efficiency of practically $100 \%$ is obtained. According to complementary studies, the biofuels showed in Tables 2 and 3 can be used in mixtures with diesel fossil, up to $20 \%$ of Biofuel in the total mixture for Ecodiesel of sunflower 
oil (Table S2), and up to 15\% if the Biodiesel is obtained from castor oil [41]. In these blends, the viscosity values drop to the limits established in EN 14214 standards.

Table 3. Results obtained in the transesterification of castor oil. Reaction conditions: $100 \mathrm{~mL}$ of either Castor oil or Sunflower oil $\left({ }^{*}\right), 5 \mathrm{~mL}$ of ethanol, $5 \mathrm{~mL}$ of methanol and $1.0 \mathrm{~mL}$ of sodium methoxide, at $30{ }^{\circ} \mathrm{C}$ and $300 \mathrm{rpm}$. The neutralization is carried out with $0.1 \mathrm{~mL}$ of $\mathrm{H}_{3} \mathrm{PO}_{4}$. No phase separation was observed.

\begin{tabular}{cccccccc}
\hline $\begin{array}{c}\text { Time } \\
(\mathbf{m i n})\end{array}$ & $\begin{array}{c}\text { Conv. } \\
\mathbf{( \% )}\end{array}$ & $\begin{array}{c}\text { Sel. } \\
\mathbf{( \% )}\end{array}$ & $\begin{array}{c}\text { FAME } \\
\mathbf{( \% )}\end{array}$ & $\begin{array}{c}\text { MG } \\
\mathbf{( \% )}\end{array}$ & $\begin{array}{c}\text { DG } \\
\mathbf{( \% )}\end{array}$ & $\begin{array}{c}\text { TG } \\
\mathbf{( \% )}\end{array}$ & $\begin{array}{c}\text { Ecodiesel Visc. } \\
(\mathbf{c S t})\end{array}$ \\
\hline 15 & 67.3 & 44.0 & 34.1 & 9.9 & 23.3 & 32.7 & 93 \\
30 & 71.1 & 42.7 & 30.4 & 12.3 & 28.4 & 28.9 & 106 \\
45 & 73.3 & 52.0 & 40.9 & 11.1 & 21.3 & 26.7 & 64 \\
60 & 78.0 & 50.8 & 40.3 & 10.5 & 27.2 & 22.0 & 76 \\
$15^{*}$ & 58.9 & 23.2 & 19.6 & 3.6 & 35.7 & 41.1 & 12 \\
$30^{*}$ & 86.7 & 38.9 & 32.4 & 6.5 & 47.8 & 13.3 & 12 \\
$45^{*}$ & 100 & 84.3 & 70.8 & 13.5 & 15.7 & 0.0 & 11 \\
$60^{*}$ & 100 & 66.6 & 54.4 & 12.2 & 33.4 & 0.0 & 11 \\
\hline
\end{tabular}

2.2. Characterization of Biofuel Mixtures, with Fossil Diesel and Alcohols, to Allow Their Use in Conventional Compression Ignition Engines, without Any Modification

\subsubsection{Double Blends: Diesel/Biofuels}

The mixtures of oils with diesel exhibit very different viscosity values, depending on the percentages of oil in the diesel, and also depending on the oil employed. However, the rheological properties of these mixtures are hardly affected by the nature of the oils, mainly at low oil concentrations, so it is possible to obtain mixtures with a $10 \% v / v$ of oil in diesel, suitable of being use in conventional diesel engines, conforming to EN 14214. Thus, it is very remarkable that, despite the high viscosity of castor oil, it behaves analogously to sunflower oil when it is blending with diesel. In fact, considering BSO10 blends, the viscosity reached a $3.6 \mathrm{cSt}$ while a BCO10 blend reaches a viscosity value of $4.5 \mathrm{cSt}$.

Taking into account the use of different mixtures of diesel with Ecodiesel, with lower viscosity than the starting oils, higher values of fossil fuel replacement can be achieved. Thus, with sunflower oil, employed in this research as a reference for waste cooking oils (second generation biofuel), it is possible to obtain Ecodiesel (EcoSO) under the experimental conditions as in Table 3, with viscosities in the range of 12 to $15 \mathrm{cSt}$, whereas in a blend of diesel with a 30\% of EcoSO, a viscosity value of $5.1 \mathrm{cSt}$ is obtained, suitable to be employed directly in conventional diesel engines. In addition, we must not lose the perspective of how the biofuels is considered to be employed, i.e., in different mixtures, $20 \%$ in 2020, and $30 \%$ in 2030. To do so, the process described in Tables 2 and 3 seems to be the most appropriate to produce the biofuels in the most easy (and economical) way, although obviously they can be obtained with higher quality, even with a similar quality to biodiesel. However, higher concentrations of catalyst and alcohols must be used for this purpose, implying then a higher cost.

Regardless of the procedure employed for the Ecodiesel synthesis, it is important to establish what percentages of mixture with diesel can be employed in every case. Thus, for the Ecodiesel obtained with the experimental conditions indicated in Table 3 (viscosity $=64 \mathrm{cSt}$ ), the maximum mixing level for being employed in C.I. engine is $15 \%$, attaining a viscosity value of $5.8 \mathrm{cSt}$. However, if a lower viscosity Ecodiesel is employed, either EcoCO or EcoSO, obtained by using higher concentrations of catalyst and alcohol, they can be employed even up to 30\% blending with diesel, Figure 2 . These results show that EcoCO exhibits similar rheological properties as $\mathrm{BCO}$ when they are blended with diesel [41], up to $25 \% v / v$. 


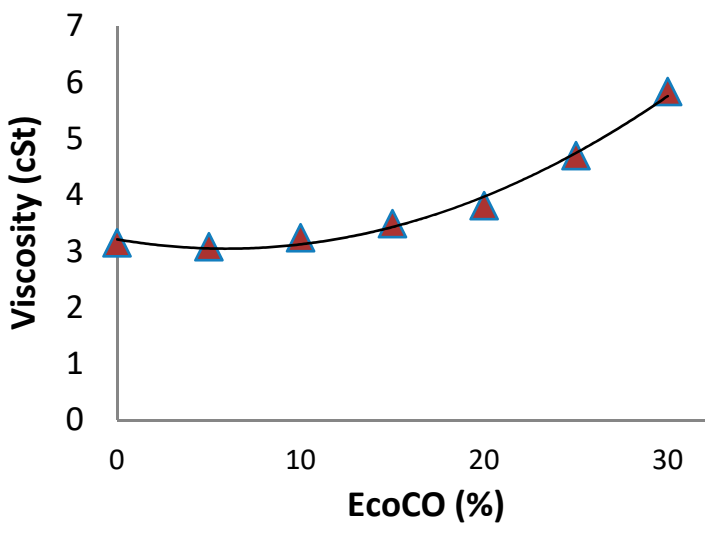

(a)

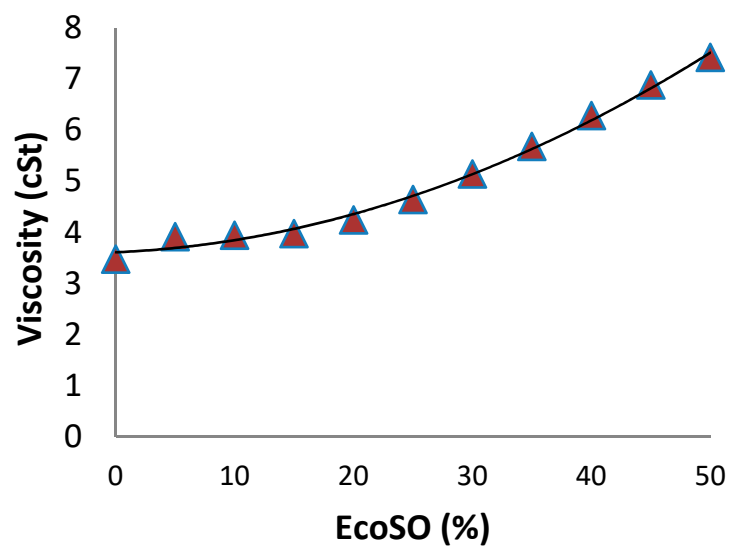

(b)

Figure 2. Kinematic viscosity values (cSt), obtained at $40^{\circ} \mathrm{C}$, of mixtures composed for (a) increasing amounts of castor oil ecodiesel (EcoCO) in fosil diesel, and (b) increasing amounts of sunflower oil ecodiesel (EcoSO) in fosil diessel.

\subsubsection{Triple Blends: Diesel/Biofuels/Short Chain Alcohols}

In Figure 3, the viscosity values of different triple blends Diesel/EcoSO/alcohol, are collected. Two different alcohols, ethanol and 2-propanol have been employed. First of all, it should be highlighted that the blends were prepared adding increasing amounts of a mixture of Ecodiesel/alcohol 4:1 $(v / v)$. This 4:1 proportion has the maximum amount of ethanol for the blends to be stable, taking into account that the subsequent adding to diessel fuel will be further dilute the mixture (triple blends). Thus, these Ecodiesel/alcohol mixtures present a viscosity of $7.75 \mathrm{cSt}$ with ethanol y $7.32 \mathrm{cSt}$ with 2-propanol, so they cannot be applied as biofuels because of their high viscosity values (the diesel engine works at viscosities between 3-5 cSt, according to EN 14214). However, by adding different amount of diesel to these double mixtures, a sufficient reduction of the viscosity values was achieved, in the range of 3-5 cSt, which can be perfectly employed in a C.I. engine. Taking into account the viscosity results shown in Figure 3a, with a blend diesel/EcoSO/ethanol 60/30/10, it is possible to incorporate a $40 \%$ of renewable compounds as diesel additive, which is almost the double than that achieved with the blends diesel/Ecodiesel, where a maximum of $25 \%$ of EcoSO in diesel was obtained (Figure 2b). Regarding the data obtained with 2-propanol, Figure 3a, with only a $40 \%$ of diesel in the blend, we are able to obtain a biofuel with a suitable viscosity for being employed in C.I. engines, replacing a $5 \%$ more of diesel than using ethanol.

Then, the high capability shown by alcohols to reduce the viscosity of their blends with EcoSO can be also employed to optimize the blends of these alcohols with oils. This can be especially useful in the case of castor oil, which according to the data collected in Figure 4, has a greater mixing capability with alcohols than EcoCO itself. This behavior can be explained by the high content of hydroxyl groups of Castor oil, exceptional among fatty acids, which confer it a high capability for being blended with alcohols, including ethanol, in any proportion. The appropriate viscosity values, lower than $5.0 \mathrm{cSt}$, are reached when the concentration of alcohols in the blends are higher than $60 \%$. However, in EcoCO/alcohol blends, Figure $4 \mathrm{~b}$, the expected decrease in viscosity was not observed, taking into account the much lower viscosity of the Ecodiesel, compared to the starting Castor oil. Therefore, there is no advantages in using EcoCO instead of pure Castor oil.

Furthermore, as can be seen in Figure 4, any blend of $\mathrm{CO}$ either with ethanol or isopropanol, in which the alcohol content was above $65 \%$ exhibits the appropriate viscosity for being use in conventional diesel engines. This is especially interesting in the case of ethanol, due to its renewable character, which means that these mixtures of castor oil with ethanol, 35/65, are 100\% renewable biofuels. However, it is foreseeable that mixtures of $\mathrm{CO}$ with alcohols would not have an adequate 
behavior in terms of the power reached and the high consumption of biofuel, due to the low calorific power of the alcohols.

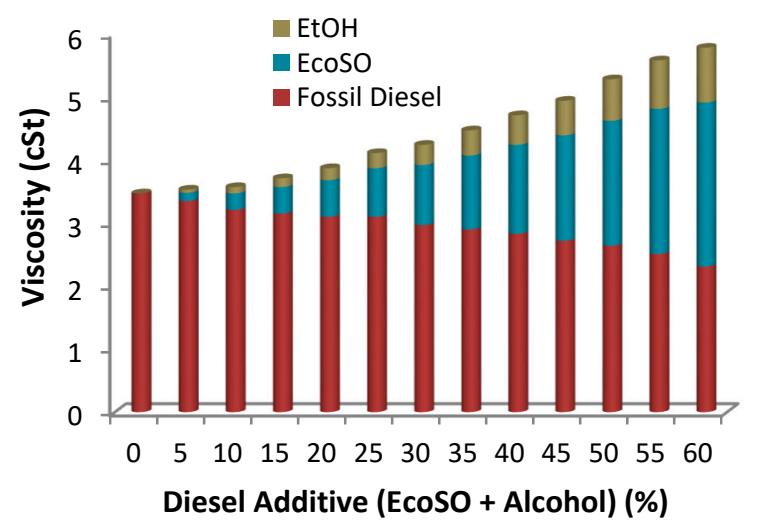

(a)

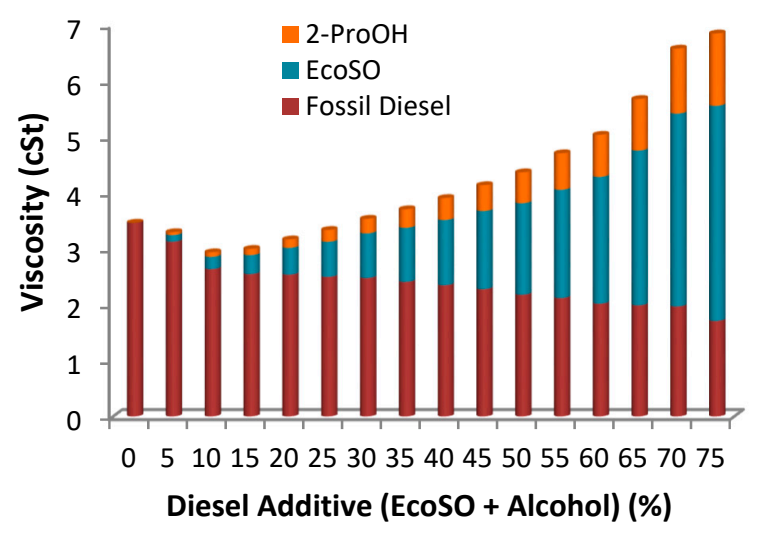

(b)

Figure 3. Viscosity values of the different triple mixtures obtained blending conventional Fossil Diesel, Ecodiesel from sunflower oil (EcoSO) and either ethanol (a) or 2-Propanol (b). In all the cases, the Ecodiesel/alcohol ratio is constant, with $25 \%$ alcohol.

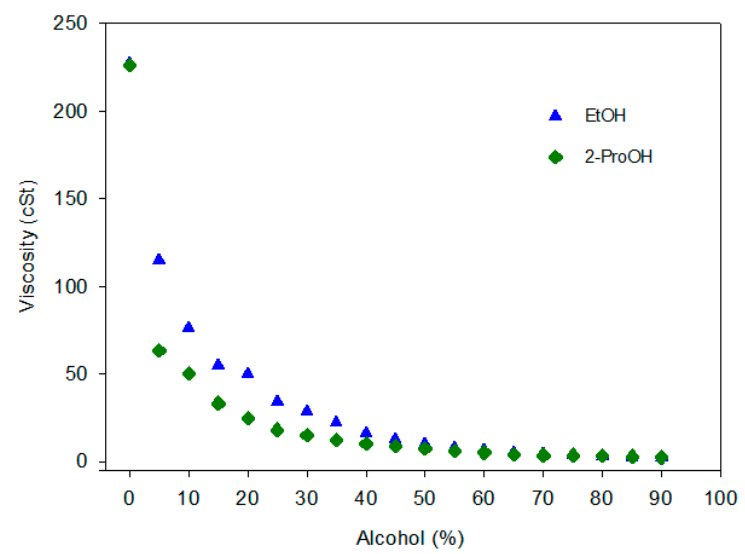

(a)

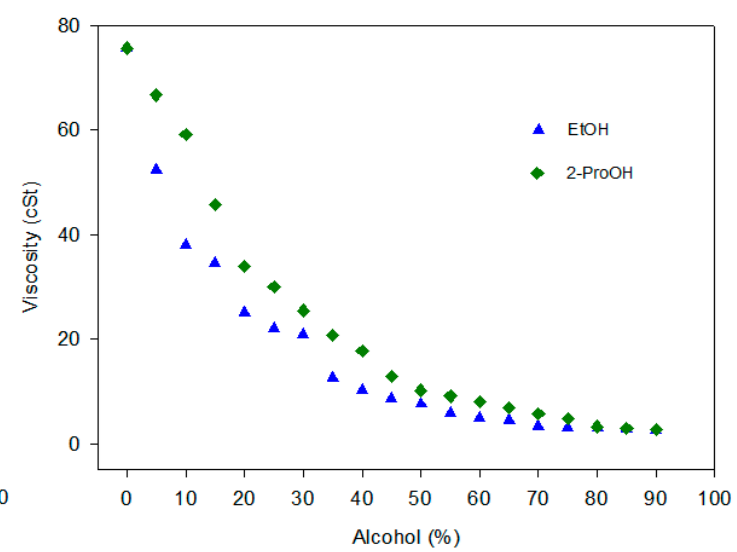

(b)

Figure 4. Viscosity values of the different double mixtures obtained blending ethanol (1.3 cSt) or isopropanol (1.63 cSt) with castor oil (227.0) cSt (a) and with the Ecodiesel from castor oil (EcoCO) (b). 
This behavior makes possible the assumption that triple blends diesel/EcoCO/alcohol and diesel/CO/alcohol can be employed as biofuels. In this respect, the triple mixtures diesel/EcoCO/ethanol and diesel/EcoCO/2-propanol have been prepared by blending fossil diesel with increasing amounts of a 1:1 blend of EcoCO/alcohol, and the viscosity values obtained for those blends are shown in Figure 5.

According to the results shown in Figure 5a, it is possible to incorporate a 40\% diesel additive, e.g., $60 / 20 / 20$ in the blend diesel/EcoCO/ethanol, so it is possible to achieve a higher substitution of diesel fuel than that achieved with the double blends diesel/Ecodiesel. Furthermore, no differences in the viscosity values obtained for the blends using either ethanol or 2-propanol were observed (Figure 5).

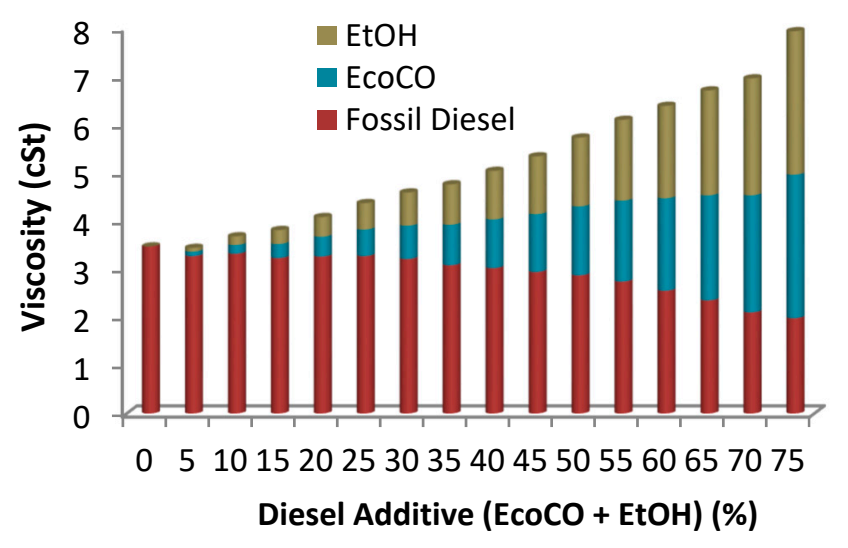

(a)

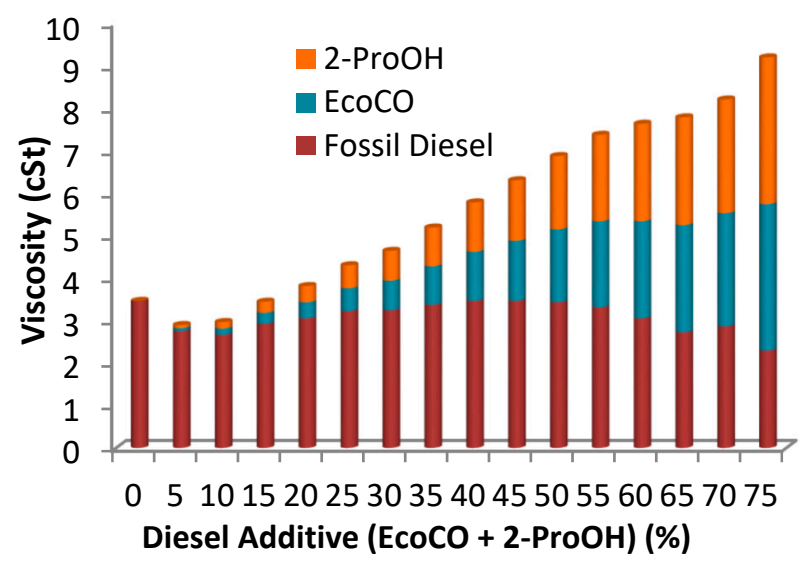

(b)

Figure 5. Viscosity values of the different triple mixtures obtained blending Ecodiesel from castor oil (EcoCO), a conventional diesel and either ethanol (a) or isopropanol (b). In all cases, the Ecodiesel/alcohol ratio is $1: 1$.

However, when Castor oil is directly employed in these triple blends, diesel/CO/alcohol, a different behavior depending on the alcohol employed is observed. As can be seen in Figure 6, for blends diesel/Castor oil/alcohol, the replacement of fossil diesel by diesel additive in amounts higher than $20 \%$ is not possible, e.g., $80 / 10 / 10$. This fact is due to the low solubility of ethanol and diesel. However, if 2-propanol is employed, a $40 \%$ of diesel fuel can be replace by diesel additives, as can be seen for the blend 60/20/20, diesel/Castor oil/2-propanol. 


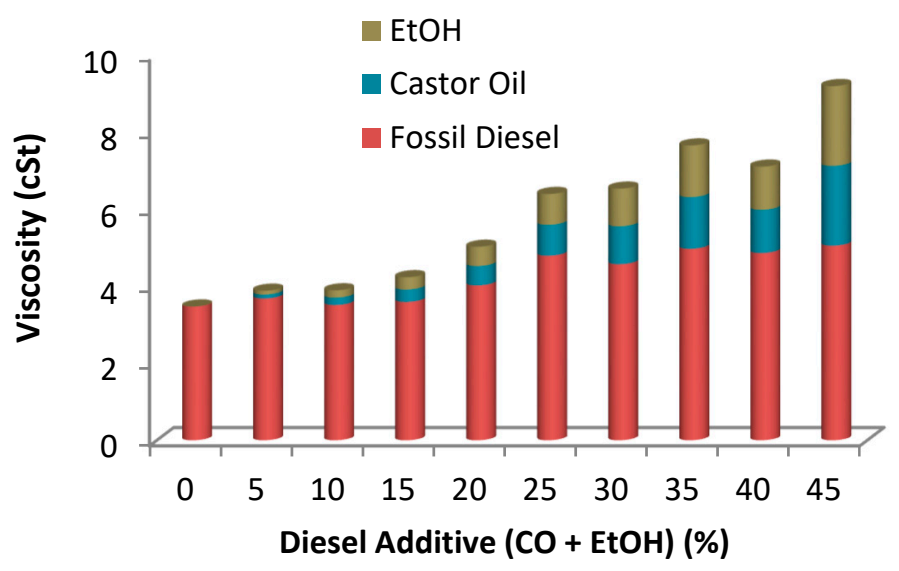

(a)

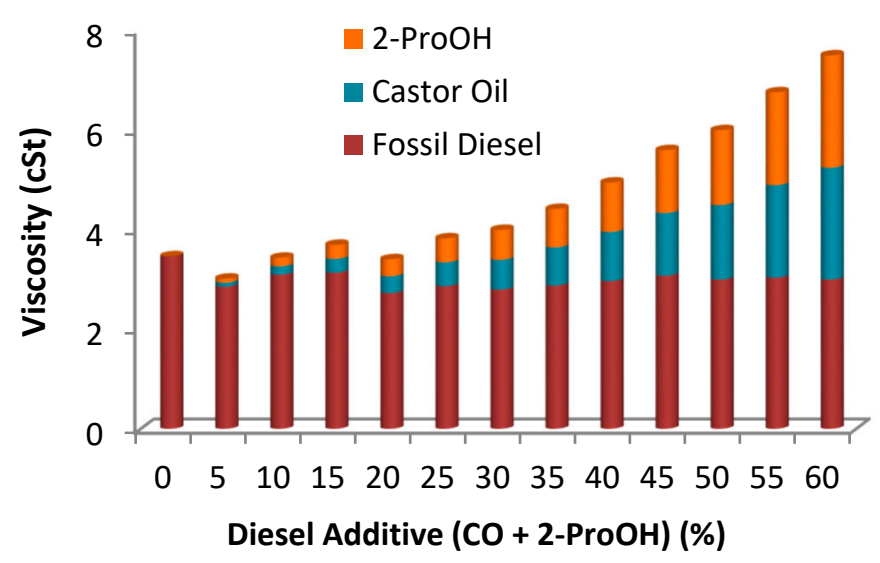

(b)

Figure 6. Viscosity values of the different triple mixtures obtained blending Castor Oil (CO), fossil diesel and either ethanol (a) or isopropanol (b). In all cases, the Ecodiesel/alcohol ratio is constant, 1:1.

These observations are really important, since Castor oil can be employed directly in the blends mixing with 2-propanol up to $40 \%$ of the total blend. Thus, there is no need to carry out the transesterification of this oil in order to get a biofuel from this raw material.

\subsection{Evaluation of Different Biofuels from Their Behavior in a Conventional Internal Combustion Engine}

\subsubsection{Double Blends Diesel/Biofuels}

At this point, it must be indicated that the physico-chemical properties of Ecodiesel (corrosion, calorific value, density, cetane index, viscosity and several properties of biofuels at low temperatures) to be employed as biofuel, are similar to those exhibited by Biodiesel. Therefore, only a very short number of rheological properties are relevant enough for being taken into account, considering its application in motor tests. These properties, i.e., viscosity, pour point (PP) and cloud point (CP), are collected in Table 4 for the different blends here studied. In principle, all the blends shown in Table 4 can be employed as biofuels in conventional diesel engines without any modification. However, the presence of MG in the Ecodiesel slightly increases the viscosity values of the mixtures, being this fact more noticeable in blends with more than $40 \%$ of Ecodiesel. In this sense, it is not advisable the use of double blends in which Ecodiesel is present in a percentage higher than $50 \%$. 
Once the reological properties were obtained, all the blends collected in Table 4 were tested in an internal combustion engine. For a better comparison, one more experiment at the same conditions but operating with a conventional diesel, was also carried out.

Table 4. Rheological properties of diesel/biofuel blends, either with EcoSO, or conventional Biodiesel from sunflower oil (BSO).

\begin{tabular}{ccccc}
\hline Blends & Biofuel in Blend $(\%)$ & Viscosity $(\mathbf{c S t})$ & Pour Point $\left({ }^{\circ} \mathbf{C}\right)$ & Cloud Point $\left({ }^{\circ} \mathbf{C}\right)$ \\
\hline BSO10 & 10 & 3.17 & -15 & -10 \\
BSO20 & 20 & 3.30 & -10 & -12 \\
BSO30 & 30 & 3.50 & -10 & -12 \\
BSO40 & 40 & 3.83 & -9 & -11 \\
BSO50 & 50 & 4.16 & -9 & -8 \\
EcoSO10 & 10 & 3.93 & -11 & -10 \\
EcoSO20 & 20 & 4.42 & -10 & -9 \\
EcoSO30 & 30 & 5.15 & -9 & -8 \\
EcoSO40 & 40 & 6.86 & -9 & -7 \\
EcoSO50 & 50 & 7.13 & -8 & -6 \\
\hline
\end{tabular}

The results of power generation and opacity (contamination parameter) obtained with all the double blends, diesel/Biodiesel, are shown in Figure 7. First of all, it can be seen that at $4 \mathrm{~kW}$ of Power demand, the highest Power Generation is achieved by the engine, regardless of the biofuel employed. In addition, all the blends exhibited similar values of Power generation, which was also analogous to that exhibited by the fossil diesel. However, considering the opacity parameter, it is highlighted that the lowest opacity value was obtained with the BSO50 blend, which presents also the highest content of Biodiesel.

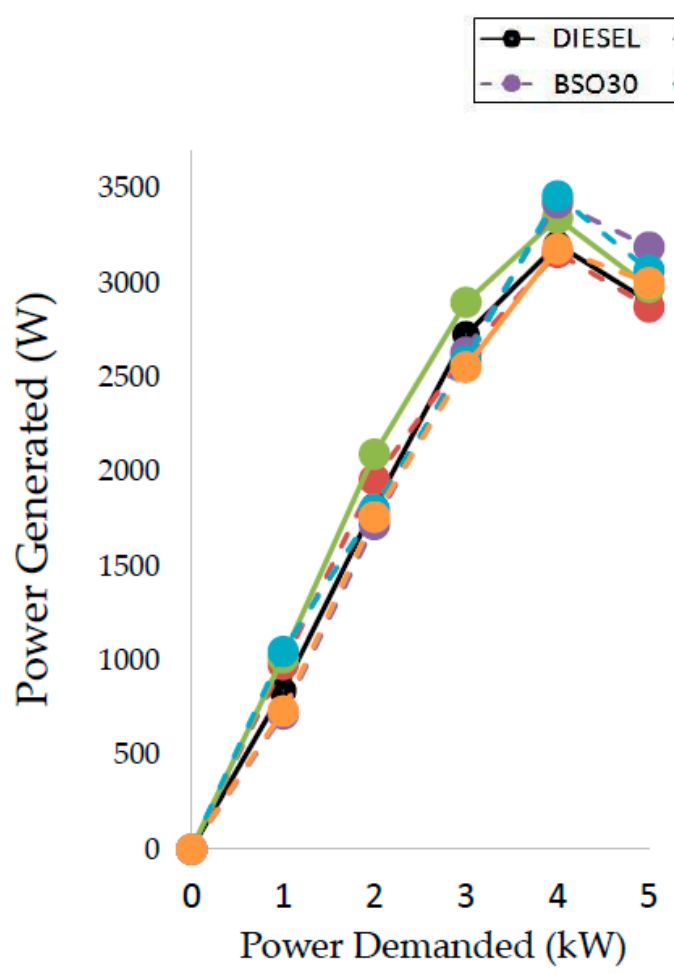

(a)
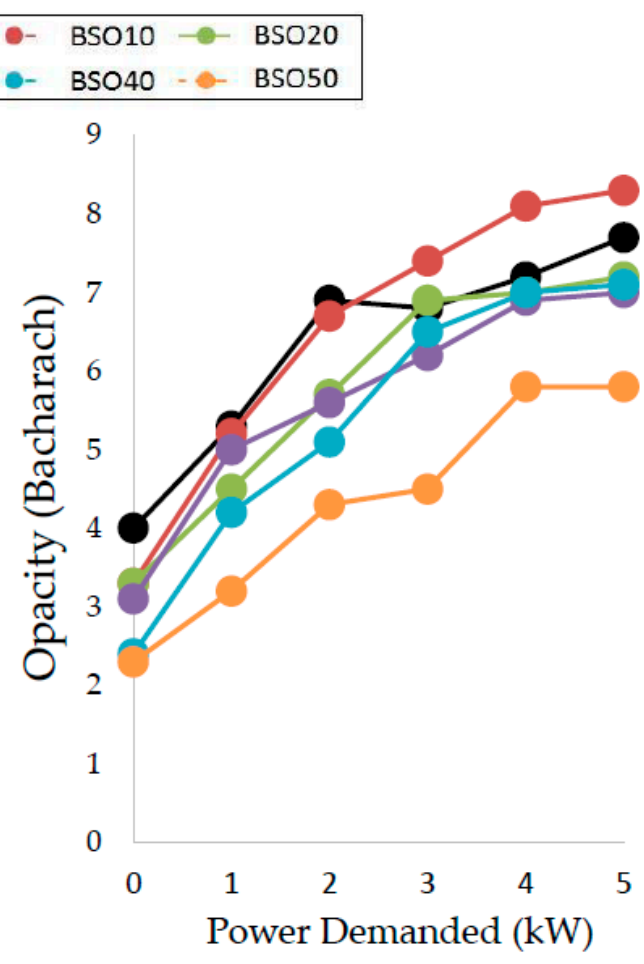

(b)

Figure 7. (a) Power generated (in Watts), based on the power demanded (in kWatts) and (b) Opacity values generated in the smokes (in Bacharach units) as a function of the power demanded of different double mixtures of Fossil Diesel with Biodiesel of Sunflower Oil (BSO). 
The double blends diesel/EcoSO also exhibited a better power generated values than the fossil diesel at high power demands, although their behavior at power demands of 1,2 and $3 \mathrm{kWatts}$ is pretty similar, even with the lowest amount of EcoSO in the blend, Figure 8a. Furthermore, the values of opacity are better than that obtained with fossil diesel and, in general, better than those obtained with the diesel/biodiesel blends, Figure $8 \mathrm{~b}$.

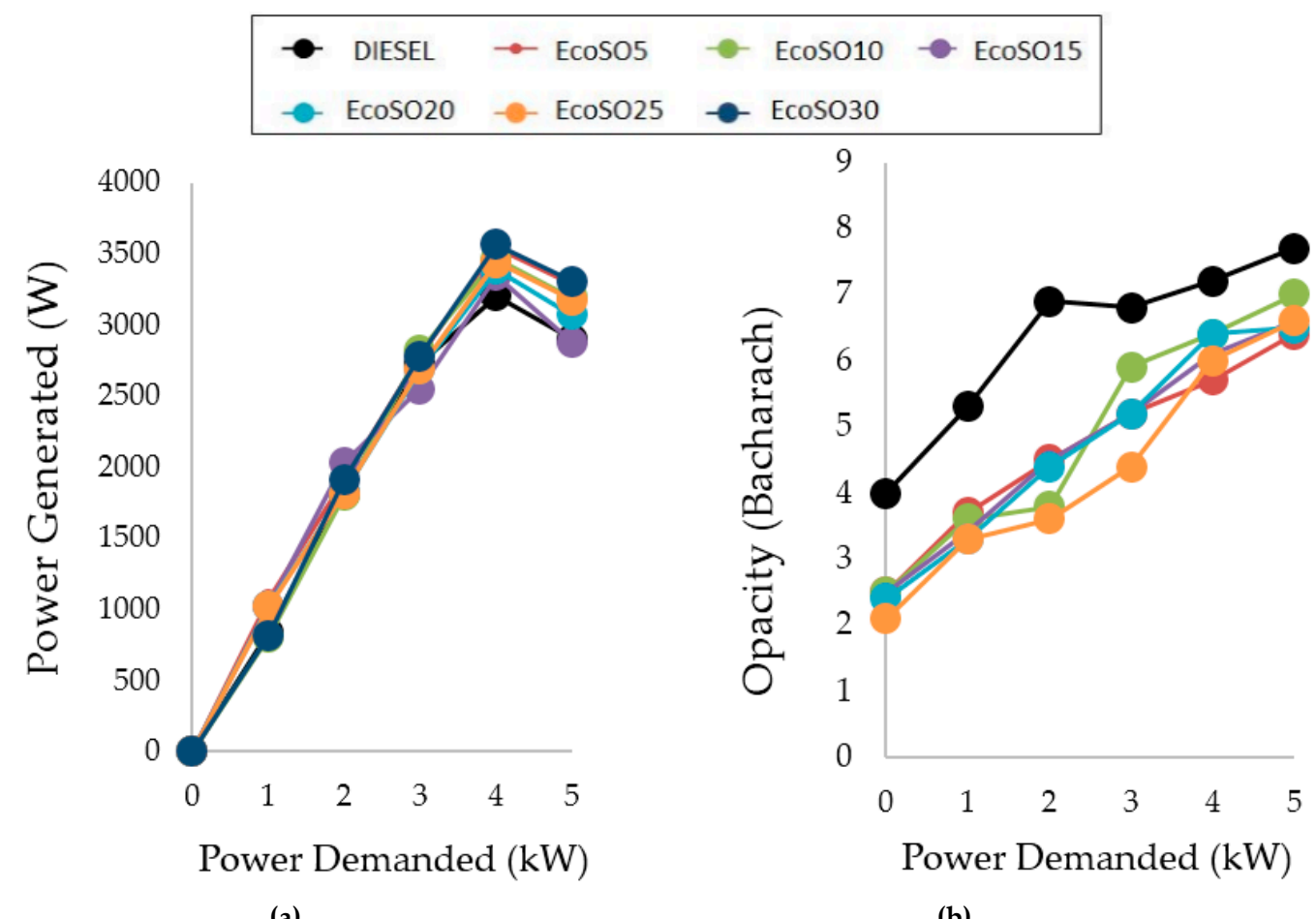

(a)

(b)

Figure 8. Results obtained by using different mixtures of Ecodiesel from sunflower oil with diesel fossil: (a) Power values generated (in Watts), based on the power demanded (in kWatts). (b) Opacity values generated in the smokes (in Bacharach units) as a function of the power demanded.

\subsubsection{Triple Blends: Diesel/Biofuels/Short Chain Alcohols}

The behavior of the more characteristics triple blends diesel/Ecodiesel/alcohol has been investigated to estimate the influence of the percentages of Diesel Additive (Ecodiesel + alcohol) in the rheological properties abovementioned, i.e., viscosity and pour point and cloud point temperatures. Thus, the results obtained for the most characeristic blends are compiled in Table 5.

Table 5. Rheological properties of triple blends diesel/biofuel/alcohol, in the proportions indicated as percentages.

\begin{tabular}{ccccc}
\hline Entry & Diesel/Biofuel/Alcohol (\%) & Viscosity (cSt) & Pour Point $\left({ }^{\circ} \mathbf{C}\right)$ & Cloud Point $\left({ }^{\circ} \mathbf{C}\right)$ \\
\hline 1 & Diesel (100) & 3.47 & -19 & -4 \\
2 & Diesel/EcoSO/EtOH (50/40/10) & 4.72 & -9 & -7 \\
3 & Diesel/EcoSO/2-ProOH (35/50/15) & 5.20 & -12 & -9 \\
4 & Diesel/EcoCO/2-ProOH (50/25/25) & 5.60 & -13 & -11 \\
5 & Diesel/CO/EtOH (50/25/25) & 5.93 & -7 & -6 \\
6 & Diesel/CO/2-ProOH (50/25/25) & 5.81 & -8 & -5 \\
\hline
\end{tabular}

The same as with double blends, the triple ones were tested in a diesel combustion engine and the results of power generated, opacity and consumption are shown in Figures 9 and 10. On one hand, the power generated is similar to that obtained with fossil diesel, mainly up to $3 \mathrm{~kW}$ of power demanded. However, two different behaviors have been observed from $4 \mathrm{~kW}$, and it is related to the 
ethanol taking part of the mixture. As it was explained before, ethanol has a low calorific power. In fact, the higher the amount of ethanol in the blend, the lower power generated at $5 \mathrm{~kW}$ (entry 5, Figure 9).

On the other hand, it is noteworthy the results related to the opacity for all the triple blends here studied. These opacity values are quite lower than that obtained with fossil diesel, indicating the great importance of these blends to reduce the emissions of pollutants. Among all of these blends, the behavior of the Castor oil is surprising, no matter with which alcohol is blended. In fact, in addition to the lowest values of opacity, the lowest consumption in $\mathrm{L} / \mathrm{h}$ were achieved at high power demanded, even better than that obtained with fossil diesel, Figure 10.

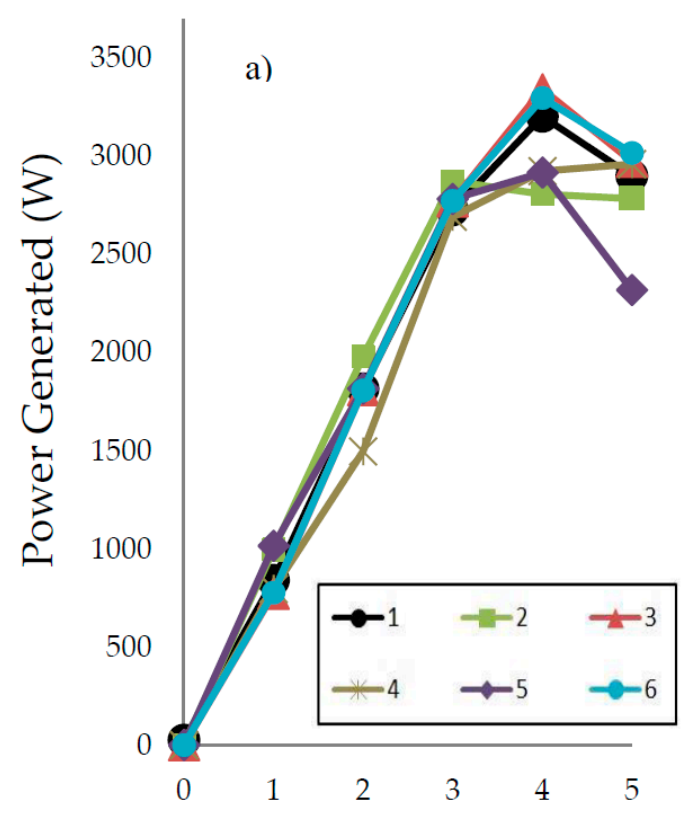

Power Demanded $(\mathrm{kW})$

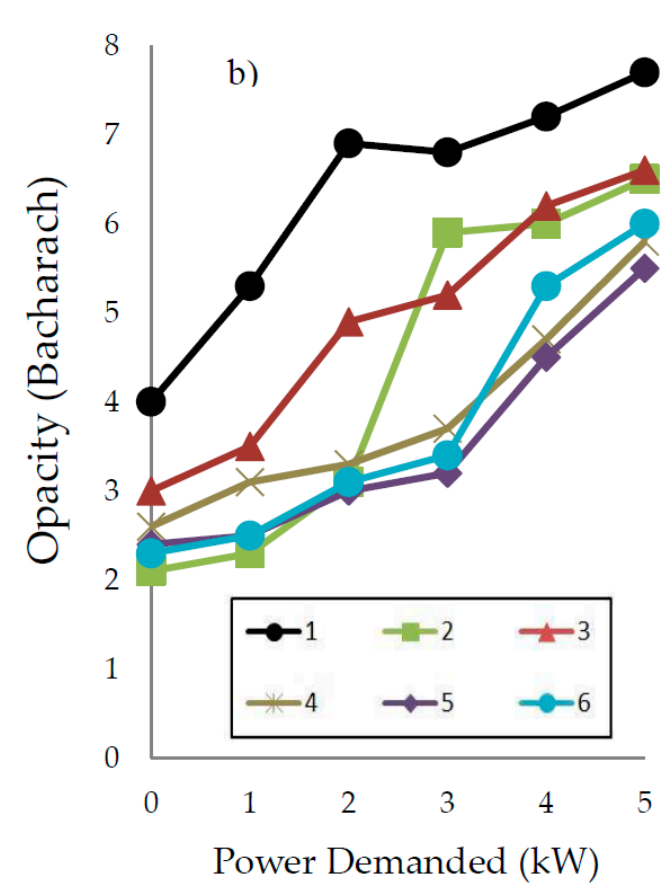

Figure 9. (a) Power generated values (in Watts), based on the power demanded (kWatts) and (b) Opacity values generated in the smokes (in Bacharach units) as a function of the power demanded of the blends of Table 5.

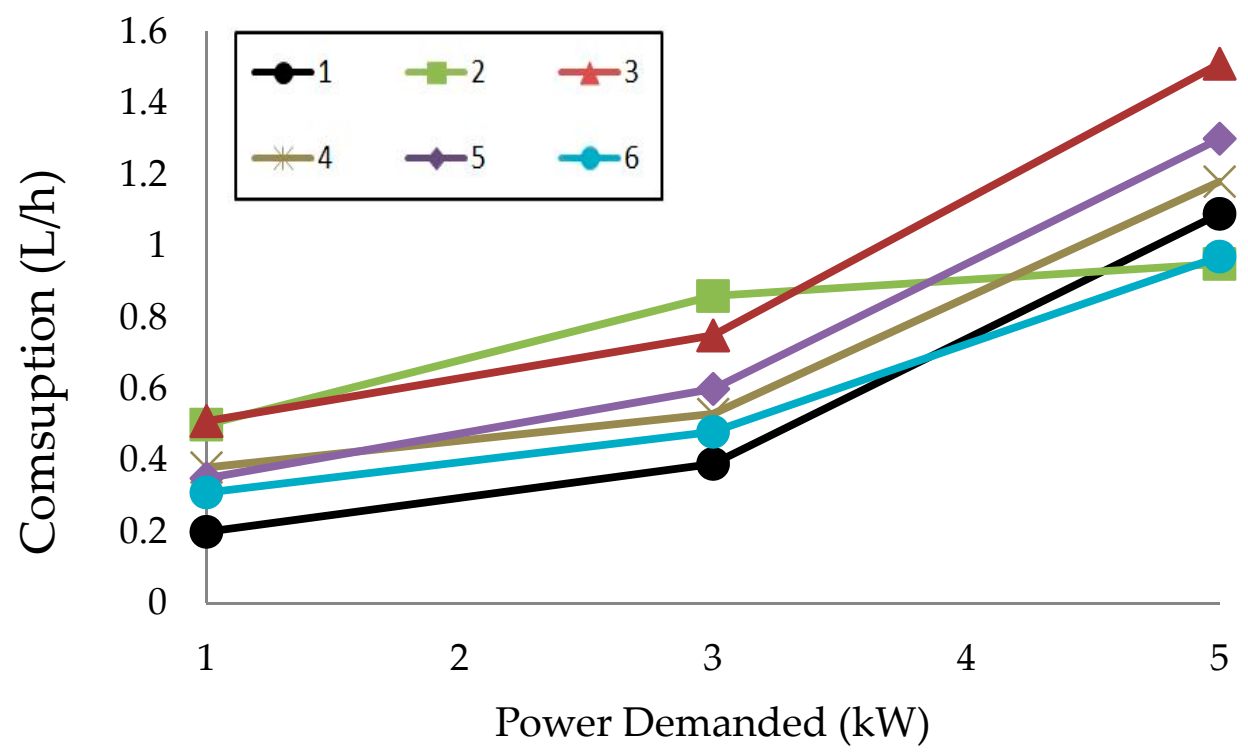

Figure 10. Consumption values of the blends in Table 5 as function of the power demanded of the engine. 


\section{Discussion}

\subsection{Synthesis of Ecodiesel by Kinetic Control of the Conventional Procedure of Biodiesel Production}

From the results here obtained, we can conclude that among all the available procedures to reduce the viscosity of the oils by chemical reaction, the selective alcoholysis exhibits the greater atomic efficiency $(100 \%)$, taking full advantage of the triglyceride molecule as biofuel [21,22]. As can be observed from Tables 1-3, by this procedure, the viscosity of the Ecodiesel is slightly higher than that exhibited by the biodiesel. This fact can be explained because the total alcoholysis generates three molecules of FAME. But, in exchange, glycerol generation, in a $10 \%$ by weight of the total biodiesel produced, is avoided.

Another important aspect from the economical point of view is that the synthesis of biodiesel needs, in general, more energetic reaction conditions. In fact, complementary studies about the Ecodiesel production [44], Table S2, have also shown that the reaction temperatures in the range of 20 to $60{ }^{\circ} \mathrm{C}$, produce very little influence on the biofuel obtained, since the viscosity in this range is reduced by less than $10 \%$. This fact implies that the activation energy in the alcoholysis of the secondary carbon of glycerol (position 2) is higher than corresponding to the activation of the primary alcohols (positions 1 and 3 of glycerol). This, among other things, would justify that both processes take place through a different reaction mechanism. From a practical point of view, this implies that the synthesis of Ecodiesel, regardless of other parameters involved, it should always be performed in the range $20-40{ }^{\circ} \mathrm{C}$, usually at room temperature. Furthermore, as can be seen in Table 2, the use of EtOH together with $\mathrm{MeOH}$ allow the 1,3-selective transesterification over sodium methoxide, attaining an Ecodiesel similar to that obtained with lipases, improving the process from an economic point of view.

In addition, another important aspect in the evaluation of the homogeneous catalytic synthesis of Ecodiesel here reported is related to its application to waste cooking oils. This process can be applied to waste oils subjected to a very simple cleaning process, since after the synthesis reaction of the Ecodiesel it is necessary to carry out a very simple filtering operation, to eliminate the salts of alkaline phosphates produced by the reaction with phosphoric acid. In the filtering process, the solid residues usually mixed with the wasted oil are also easily eliminated. In other words, biofuels can be "cleaned" in the same synthesis process of Ecodiesel. Therefore, with pure oils, the only waste is practically reduced to the $\mathrm{Na}_{3} \mathrm{PO}_{4}$ salts produced in the last neutralization step. Furthermore, the presence of ethanol as a co-reactant or solvent of methanol, works very positively because it improves the viscosity, and prevents that methanol becomes separate of the biofuel.

Everything raised above leads us to conclude that the production of Ecodiesel in mild conditions, employing homogeneous basic catalysts improves by far the previous studies which implies the use of lipases [23-26] or heterogeneous basic catalysts [28,29], not only from a technical point of view but also form the economic one, above all if we consider that this Ecodiesel can be also employed as Biofuel in different double and triple blends.

\subsection{Evaluation of Different Biofuels from Their Behavior in a Conventional Internal Combustion Engine}

From the oils here studied as raw materials in the Ecodiesel production, sunflower oil and castor oil, both Ecodiesel produced, EcoSO and EcoCO, exhibited similar rheological properties as those described in the literature for the Biodiesel from Castor oil [41], as they can be mixed in a $25 \%$ with fossil diesel, Figure 2, to run in conventional diesel engines. However, it is possible to achieve similar, or even higher, replacement of fossil diesel using pure castor oil in triple mixtures with alcohols. The peculiar structure of Castor oil allows a high solubility with both, fossil diesel and alcohols, including ethanol (Figure 4). Thus, triple mixtures can be obtained with Castor oil (Figure 6) with a high level of fossil diesel replacement, with no need of transforming the starting oil into Ecodiesel (Figures 4 and 5).

Taking into account the two different alcohols proposed in this research, and, according to the results shown in Figures 5 and 6, if ethanol is employed in the triple mixtures, the EcoCO favors a higher substitution of fossil diesel than the use of pure Castor oil, 60/20/20 and 80/10/10, respectively. 
However, if isopropanol is employed, similar results are obtained with EcoCO and pure CO. Anyway, a $40 \%$ of fossil diesel substitution was always achieved.

These double and triple blends have been evaluated according to the viscosity, as this parameter gives information about which ones can be considered for its use in a diesel engine, as the limits of viscosity required by conventional diesel engines are in the range 3-7 cSt, although European regulations (EN 14214) establish the interval 3-5 cSt, Figures 3-6.

Regarding the behavior of the blends at low temperatures, Table 5, conventional biodiesel and ecodiesel, in double and triple mixtures, solidify at temperatures around $-10{ }^{\circ} \mathrm{C}$ and are completely frozen at temperatures around $-12{ }^{\circ} \mathrm{C}$. In contrast, the corresponding temperatures for diesel fossil are around -16 to $-18{ }^{\circ} \mathrm{C}$, for pour point and cloud point, respectively. Thus, for the values here obtained, it can be observed that in blends whose percentage of biofuel is higher, the temperatures of pour point and cloud point are higher, solidifying before. Independently on the slightly worst temperatures of pour and cloud point than those exhibited by diesel, the blends studied in the present work gave acceptable results for environmental conditions where the temperatures are not reduced below $-10{ }^{\circ} \mathrm{C}$. In addition, the use of any alcohol as an additive would influences positively these parameters, since its addition promotes a better performance against low temperatures.

The blends, which meet the requirements for being employed as fuel in diesel engines, were tested at different values of power demanded. As can be seen in Figures 7 and 8, independently of the biofuel tested, a stabilization of the generated power values takes place above $4 \mathrm{~kW}$ of demanded power. Likewise, the values of power generated are slightly higher when blends with Ecodiesel were employed, especially in the proportions $20 \%$ and $30 \%$, Figures 7 a and 8 a.

About the pollution produced during the combustion of the different samples, the results show that the higher the power demanded, the higher the emission of pollutants, as it was expected. In fact, an increase in the power demand from a power equivalent to the engine working at idling speed to the highest demand of 4 or $5 \mathrm{~kW}$, the soot formation doubles. However, it is very remarkable that for blends diesel/biodiesel with biodiesel content higher than 10\% (BS20, BS30, BS40 and BS50) and blends diesel/Ecodiesel with Ecodiesel content higher than 5\%, the opacity values obtained were always lower than that obtained with fossil diesel, Figures $7 \mathrm{~b}$ and $8 \mathrm{~b}$.

Regarding the triple blends diesel/biofuel/alcohol, the power generated values and the opacity as a function of the power demanded are shown in Figure 9. On one hand, it should be noted that all the samples exhibited similar values of power generated than diesel fuel (Figure 9a), although those in which ethanol is employed as alcohol showed the lower ones, especially the blend diesel/CO/EtOH $(50 / 25 / 25)$. However, if 2-propanol is employed, independently on the biofuel, EcoSO, EcoCO or CO, very good results of power generated were obtained.

On the other hand, it must be remarked the surprisingly low opacity values obtained with all the triple blends tested, more than $10 \%$ lower than the opacity obtained with diesel, Figure $9 \mathrm{~b}$.

According to the engine fuel consumption, the results in Figure 10 show that EcoSO in triple blends with isopropanol exhibit higher consumption than diesel, whereas blended with ethanol exhibit lower consumption than diesel. For its part, the blends with EcoCO and $\mathrm{CO}$ behave the opposite, i.e., a lower consumption was obtained using 2-propanol. Thus, considering the results previously exposed, the triple blend diesel/CO/2-proOH (50/25/25) exhibit the best performance, with higher power generation, lower emission of pollutants and also lower fuel consumption, indicating its feasibility for being employed in diesel engines.

\section{Materials and Methods}

\subsection{Evaluation of Sodium Methoxide as Homogeneous Catalyst in the Selective Alcoholysis to Obtain Ecodiesel}

The selective alcoholysis of the Sunflower oil (food quality) and Castor oil (Panreac, Castellar Del Valles, Spain) were carried out over commercial sodium methoxide (Panreac, Sodium methylate solution 30\% in methanol PS) as homogeneous catalyst. The reactions were performed in a $250 \mathrm{~mL}$ 
flask immersed in a temperature-controlled water bath, at atmospheric pressure using methanol as alcohol. Different reaction conditions have been studied, such as temperature, $20-60{ }^{\circ} \mathrm{C}$, and reaction time, Figure 11.

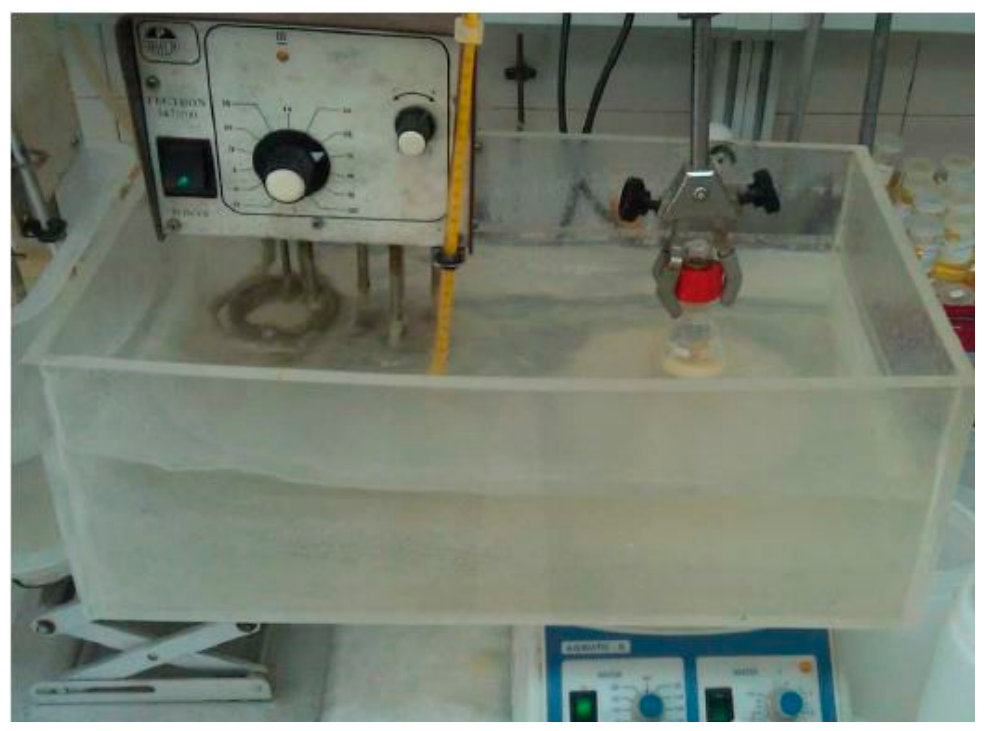

Figure 11. Experimental dispositive for the transesterification reaction.

In general, $120 \mathrm{~mL}$ of oil $(0.1 \mathrm{~mol})$ were mixed with variable proportions of methanol and sodium methoxide. The changes are easily visualized as a ratio, for example, 100/10/1 indicates $100 \mathrm{~mL}$ of oil, $10 \mathrm{~mL}$ of methanol and $1 \mathrm{~mL}$ of sodium methoxide. Variable amounts of ethanol are sometimes also incorporated in some experiments, which act as a solvent, given its lower activity with respect to methanol. It has been taken as standard measure that $0.1 \mathrm{~mol}=91.0 \mathrm{~g}$ of oil. The weigh was performed on a Mettler AJ50 precision balance (precision of $\pm 0.01 \mathrm{~g}$ ), depositing the sample directly into a $250 \mathrm{~mL}$ two-neck round bottom flask.

\subsection{Determination of the Content of FAMEs, FAEEs and Glycerides (MG, DG and TG) in the Reaction Products by Gas Chromatography}

The determination of the content of methyl esters, ethyl esters and different glycerides in the biofuel samples has been carried out by a chromatographic method developed in previous researches [23]. Thus, an HP 5890 Series II gas chromatograph with a HT5 ( $25 \mathrm{~m} \times 0.32 \mathrm{~mm}$ I.D $\times 0.1 \mu \mathrm{m}$, SGE, Supelco) Aldrich Chemie capillary column and equipped with a flame ionization detector (FID) was employed. Cetane (n-hexadecane) is used as an internal standard

This method basically consists of a modification and integration of two official methods, UNE EN ISO 14103 (esters) and UNE EN ISO 14105 (glycerides), to quantify the content of glycerol, ethyl esters and glycerides (mono, di and triglycerides), respectively. The ethyl esters of palmitic acid, stearic acid, oleic acid, linoleic acid, and linolenic acid were commercially obtained from AccuStandard (New Haven, CT, USA), and hexadecane (cetane) was obtained from Sigma-Aldrich (St. Louis, MO, USA).

Considering that castor oil or sunflower oil are constituted by a mixture of fatty acids (mainly linoleic, oleic, palmitic, and stearic acids, in sunflower oil, or ricinoleic in castor oil) in variable proportions, the results obtained are expressed as the relative amounts of the corresponding methyl esters (FAME, fatty acid methyl esters), monoglycerides (MG), and diglycerides (DG) that are integrated in the chromatogram. The number of diglycerides (DG) and triglycerides (TG) that have not reacted is calculated from the difference to the internal standard (cetane). Thus, the Conversion includes the total amount of triglyceride transformed (FAEE + MG + DG) in the methanolysis process, and Selectivity refers to the relative amount of FAEE + MG obtained. 


\subsection{Determination of Kinematic Viscosity of Biofuels}

The kinematic viscosity has been measured in an Ostwald-Cannon-Fenske capillary viscometer (Proton Routine Viscometer 33200, size 150), determining the time required for a certain volume of liquid to pass between two marked points on the instrument, placed in an upright position. From the flow time ( $(t)$, expressed in seconds, we obtain the kinematic viscosity expressed in centistokes, $v=C \cdot t$. Where $C$ is the calibration constant of the measurement system in $\mathrm{mm}^{2} / \mathrm{s}^{2}$, which is specified by the manufacturer $\left(0.040350 \mathrm{~mm}^{2} / \mathrm{s}^{2}\right.$ at $40{ }^{\circ} \mathrm{C}$, in this case). All measures have been carried out in duplicate and are presented as the average of both, proving that there is no greater variation of $0.35 \%$ between measures, as required by the standard ASTM (American Society for Testing and Materials) D2270-79, Method for calculating viscosity index from kinematic viscosity at 40 and $100{ }^{\circ} \mathrm{C}$.

\subsection{Determination of the Pour Point and Cloud Point of Biofuels}

Cloud point and the Pour point are determined by introducing the different double or triple samples, of different composition, in a digitally controlled temperature refrigerator for twenty-four hours; after this time the loss of transparency of the solutions is evaluated. The appearance of turbidity in the samples is indicative that the cloud point temperature has been reached (cloud point). After a progressive decrease in temperature, the samples are kept under observation until they stop flowing (pour point).

\subsection{Assessment of Energy Performance and Air Pollutant Emissions in a Diesel Engine Electric Generator, Fueled with Different Blends of Biofuels}

The mechanical and environmental characterization of a compression ignition diesel engine has been carried out, working at a rate of $3000 \mathrm{rpm}$ coupled to an AYERBE electric generator, $5 \mathrm{KVA}, 230 \mathrm{v}$ type AY4000MN, for the generation of electricity, operating at a crankshaft constant rotation rate and under different degrees of demand for electrical power. This is achieved by connecting heating plates of 1000 watts each one (Figure 12a). This diesel engine will operate at a constant rate of rotation of the crankshaft and torque, so that the different values of electrical power obtained will be an exact consequence of the mechanical power obtained after the combustion of the corresponding biofuel. Different tests are obtained by providing to the engine double and triple mixtures of different biofuels in different percentages. The electrical power generated can be easily determined from the product of the potential difference (or voltage) and the electric current intensity (or amperage), equation (1), both obtained by means of a voltmeter-ammeter $[45,46]$.

$$
\text { Electrical Power Generated }(\text { Watts })=\text { voltage }(\text { Volts }) \times \text { amperage }(\text { Amps })
$$

The consumption of the diesel engine with the different biofuels employed was calculated estimating the speed of consumption of the engine, with a given fuel, when operating under a determined demand of electric power.

On the other hand, the contamination degree is evaluated regarding the opacity of the smoke generated in the combustion process. This is obtained by using an opacimeter-TESTO 308 opacity meter-under the operating conditions studied (Figure 12b). All the results obtained with the biofuels evaluated were compared with the corresponding measurements obtained with conventional diesel. The opacimeter, is a device designed to estimate the amount of soot emitted by diesel engines. Unlike gasoline engines, where the amount of carbon monoxide $(\mathrm{CO})$ and hydrocarbons $(\mathrm{HC})$ is measured to assess the quality of combustion and toxic emissions, only the amount of coal is analyzed in diesel engines (soot). These are tiny particles in suspension which can not be treated as a gas, that is, they can not be quantified through the gas analyzer. The opacimeter is basically composed of three components: measuring chamber, analyzer and a portable terminal. The outlet of the exhaust pipe of the engine is connected, through a pipe and a hose, with the measuring chamber and partial samples of the exhaust gases are taken. It is called partial since only part of the gases enter the machine and the rest is lost in 
the atmosphere. The gases enter inside a tube and through a sensor the intensity of the light (turbidity) is measured, to then calculate the density of the particles. The tube has a source of halogen light at one end and a receiver at the other so that when there is no gas inside the tube, the light intensity is not affected. The result of such measurements is reflected visually on a filter paper. Besides, this value can be expressed as a percentage of Opacity (being 100\% totally cloudy and $0 \%$ totally clear) or as an equivalent number called the $k$ value (Opacity Bacharach) the scale runs from white (0 Bacharach unit) to black (9 Bacharach units), as established by ASTM D 2156-94, Standard Test Method for Smoke Density in Flue Gases from Burning Distillate Fuels [47]. It must be clarified that all the measured were repeated at least three times, attaining an experimental error lower than $5 \%$.

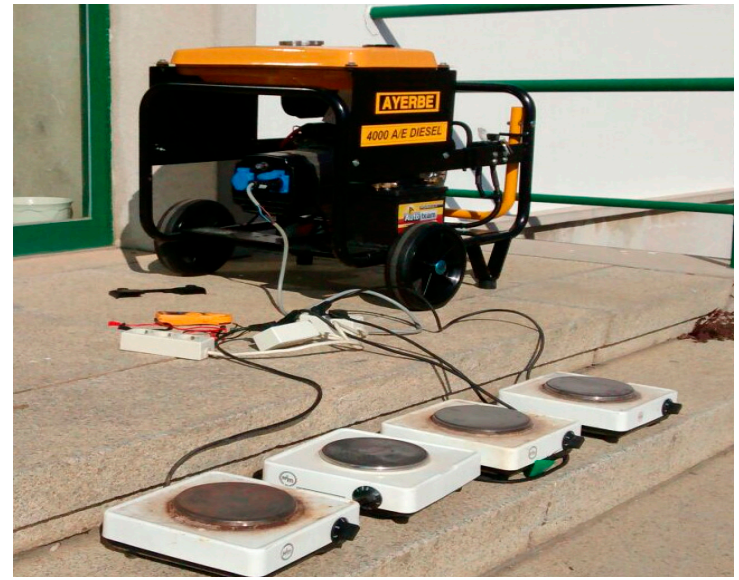

(a)
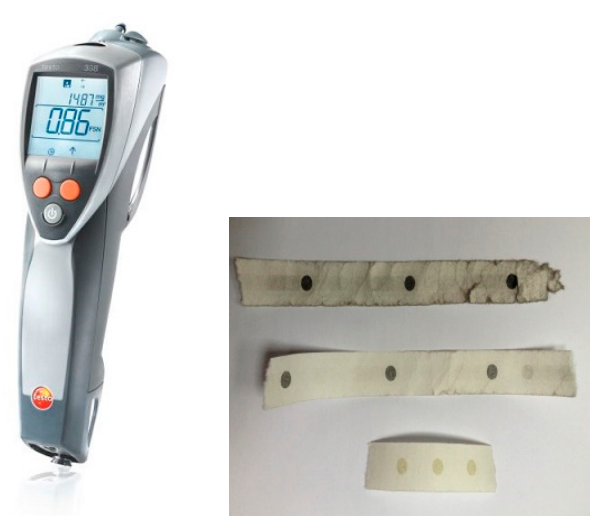

(b)

Figure 12. (a) Electrogenerator AYERBE, 5KVA, 230v tipo AY4000MN, heating plates of 1000 watts of power each and voltmeter-ammeter devise (yellow colour, on the floor); (b) TESTO 308 opacity meter, which operates as established by ASTM D 2156-94, Standard Test Method for Smoke Density in Flue Gases from Burning Distillate Fuels.

\section{Conclusions}

In this research, some Biofuels have been synthesized employing a commercial basic homogeneous catalyst, sodium methoxide, at milder conditions than those employed to obtain conventional biodiesel, to favor a selective 1,3 methanolysis of triglycerides, achieving a $100 \%$ atomic efficiency in the synthesis of Ecodiesel. In this respect, sunflower oil and castor oil have been evaluated. Besides, the behavior of diesel/biofuel blends, as well as the behavior of several triple blends, diesel/biofuel/alcohol have been also studied. Furthermore, the differences between Ecodiesel and conventional biodiesel, as well as the alcohol employed in the blends, in what proportions must be added together with fossil diesel, to obtain the rheological properties to operate in conventional diesel engines without making any modifications have been also determined. The main conclusions obtained in this research can be summarized as follows:

It has been demonstrated, for the first time, that the use of $\mathrm{EtOH}$ as solvent in the 1,3-selective transesterification of triglycerides improve the diffusion between methanol and TG, allowing its reaction at milder conditions, since an increase in the temperature of the reaction does not improve the Ecodiesel production.

Ecodiesel from both, sunflower and castor oil, has been successfully obtained at the reaction conditions: Oil/ethanol/methanol/catalyst ratio 100/5/5/1, employing sodium methoxide as homogeneous catalyst at $30^{\circ} \mathrm{C}$ and at a stirring speed of $300 \mathrm{rpm}$ and $15 \mathrm{~min}$ of reaction time.

This research has shown that the chemical route here proposed for the synthesis of Ecodiesel is able to reduce the production costs to a great extent, in comparison with enzymatic routes and heterogeneous catalysed routes. 
About the rheological properties of the double and triple blends here studied, it has been verified that the viscosity, Pour Point and Cloud Point values of the different samples allow their use as biofuels in conventional diesel engines.

The results obtained using a compression ignition diesel engine show that $4 \mathrm{~kW}$ of power demand gives the greatest engine power generation, independently on the fuel employed.

With the blends diesel/biodiesel, a $50 \%$ of fossil diesel can be replaced by a biofuel obtained from a renewable source, whereas in the blends diesel/Ecodiesel, the amount of fossil diesel that can be replaced is lower, $30 \%$. This fact is due to the presence of MG in the Ecodiesel, which increase the viscosity above $6 \mathrm{cSt}$.

The use of triple blends diesel/biofuel/alcohol allows us to increase the diesel replacement, even employing directly Ecodiesel or Castor oil. Thus, it is possible to use pure Castor oil in the proportions $50 / 25 / 25$, diesel/CO/2-propanol, in conventional diesel engines, with a performance and level of consumption like fossil diesel, but with an appreciably lower emission of pollutants. In the case of the Ecodiesel of sunflower oil, (and used cooking oils, for use as second generation biofuels) it is possible to obtain triple mixtures with any ethanol in a proportion 50/40/10 diesel/EcoSO/ethanol which also exhibits very good results in terms of consumption and emission of pollutants.

Supplementary Materials: The following are available online at http:/ / www.mdpi.com/2073-4344/9/1/40/s1, Figure S1: Chromatograms obtained in the sunflower oil alcoholysis (a). The initial sunflower oil is in black (a). Commercial diesel fuel chromatogram (b), Table S1: Viscosity values of different blends diesel/Ecodiesel from Castor oil (EcoCO), Table S2: Viscosity and Selectivity values of Ecodiesel of Sunflower oil (EcoSO) and reaction products obtained at the same reaction conditions as in Table 2, after $60 \mathrm{~min}$. The Conversion was also $100 \%$. Sel. $=\mathrm{FAE}+\mathrm{MG}$, being FAE $=$ FAME + FAEE .

Author Contributions: This research article is part of the doctoral thesis of B.H., and A.P., directed by D.L., J.M.H and F.M.B., who in general conceived and designed the experiments. C.L., J.C., A.A.R. and R.E. made substantive intellectual contributions to this study, making substantial contributions to conception and design of it, as well as to the acquisition, analysis and interpretation of data. Furthermore, D.L. and R.E wrote the paper. All the authors have been also involved in drafting and revising the manuscript, so that everyone has given final approval of the current version to be published in Catalysts Journal.

Funding: This research received no external funding.

Acknowledgments: This research is supported by the MEIC funds (Project ENE 2016-81013-R), Junta de Andalucía and FEDER (P11-TEP-7723), that cover the costs to publish in open access.

Conflicts of Interest: The authors declare no conflict of interest.

$\begin{array}{ll}\text { Abbreviations } \\ \text { FAME } & \text { fatty acids methyl esters, components of conventional biodiesel } \\ \text { DMC } & \text { dimethyl carbonate } \\ \text { FAEE } & \text { Fatty Acid Ethyl Ester } \\ \text { FAE } & \text { esters of fatty acids } \\ \text { MG } & \text { monoglycerides or monoacylglycerols } \\ \text { DG } & \text { diacylglycerols } \\ \text { TG } & \text { triacylglycerols or triglycerides } \\ \text { GC } & \text { gas chromatograph } \\ \text { CO } & \text { Castor oil } \\ \text { SO } & \text { Sunflower oil } \\ \text { BCO } & \text { Biodiesel obtained from Castor oil } \\ \text { BSO } & \text { Biodiesel obtained from Sunflower oil } \\ \text { C.I. } & \text { Compression Ignition engines } \\ \text { CP } & \text { Cloud Point } \\ \text { PP } & \text { Pour point } \\ \text { CFPP } & \text { Cold filter plugging point temperature } \\ \text { POFF } & \text { Point of occlusion of the cold filter }\end{array}$




\section{References}

1. Arutyunov, V.S.; Lisichkin, G.V. Energy resources of the 21st century: Problems and forecasts. Can renewable energy sources replace fossil fuels? Russ. Chem. Rev. 2017, 86, 777-804. [CrossRef]

2. Nigam, P.S.; Singh, A. Production of liquid biofuels from renewable resources. Prog. Energy Comb. Sci. 2011, 37, 52-68. [CrossRef]

3. Cheng, F.; Li, X. Preparation and Application of Biochar-Based Catalysts for Biofuel Production. Catalysts 2018, 8, 346. [CrossRef]

4. Chu, S.; Majumdar, A. Opportunities and challenges for a sustainable energy future. Nature 2012, 488, 294-303. [CrossRef] [PubMed]

5. Ridjan, I.; Mathiesen, B.V.; Connolly, D.; Dui, N. The feasibility of synthetic fuels in renewable energy systems. Energy 2013, 57, 76-84. [CrossRef]

6. Kumar, A.A.; Sharma, S. Potential non-edible oil resources as biodiesel feedstock: An Indian perspective. Renew. Sustain. Energy Rev. 2011, 15, 1791-1800. [CrossRef]

7. Rakopoulos, D.C.; Rakopoulos, C.D.; Giakoumis, E.G.; Dimaratos, A.M.; Founti, M.A. Comparative environmental behaviour of bus engine operating on blends of diesel fuel with four straight vegetable oils of Greek origin: Sunflower, cottonseed, corn and olive. Fuel 2011, 90, 3439-3446. [CrossRef]

8. Lapuerta, M.; Armas, O.; Herreros, J.M. Emissions from a diesel-bioethanol blend in an automotive diesel engine. Fuel 2008, 87, 25-31. [CrossRef]

9. Karabektas, M.; Hosoz, M. Performance and emission characteristics of a diesel engine using isobutanol-diesel fuel blends. Renew. Energy 2009, 34, 1554-1559. [CrossRef]

10. Atmanl1, A.; Ileri, E.; Yüksel, B. Experimental investigation of engine performance and exhaust emissions of a diesel engine fueled with diesel-n-butanol-vegetable oil blends. Energy Convers. Manag. 2014, 81, 312-321. [CrossRef]

11. Campos-Fernández, J.; Arnal, J.M.; Gómez, J.; Dorado, M.P. A comparison of performance of higher alcohols/diesel fuel blends in a diesel engine. Appl. Energy 2012, 95, 267-275. [CrossRef]

12. Navaneethakrishnan, P.; Vasudevan, D. Experimental Study on Performance and Exhaust Emission Characteristics of a C.I. Engine Fueled with Tri Compound Oxygenated Diesel Fuel Blends. Indian J. Sci. Technol. 2015, 8, 96-102. [CrossRef]

13. Yilmaz, N. Comparative analysis of biodiesel-ethanol-diesel and biodiesel-methanol-diesel blends in a diesel engine. Energy 2012, 40, 210-213. [CrossRef]

14. Yilmaz, N.; Vigil, F.M.; Donaldson, A.B.; Darabseh, T. Investigation of CI engine emissions in biodiesel-ethanol-diesel blends as a function of ethanol concentration. Fuel 2014, 115, 790-793. [CrossRef]

15. Shahir, S.A.; Masjuki, H.H.; Kalam, M.A.; Imran, A.; Ashraful, A.M. Performance and emission assessment of diesel-biodiesel-ethanol/bioethanol blend as a fuel in diesel engines: A review. Renew. Sustain. Energy Rev. 2015, 48, 62-78. [CrossRef]

16. Aydın, F.; Ogüt, H. Effects of using ethanol-biodiesel-diesel fuel in single cylinder diesel engine to engine performance and emissions. Renew. Energy 2017, 103, 688-694. [CrossRef]

17. Ghobadian, B.; Yusaf, T.; Najafi, G.; Khatamifar, M. Diesterol: An environment-friendly IC engine fuel. Renew. Energy 2009, 34, 335-342. [CrossRef]

18. Noorollahi, Y.; Azadbakht, M.; Ghobadian, B.; Noorollahi, Y. The effect of different diesterol (diesel-biodiesel-ethanol) blends on small air-cooled diesel engine performance and its exhaust gases. Energy 2018, 142, 196-200. [CrossRef]

19. Quispe, C.A.G.; Coronado, C.R.; Carvalho, J.A., Jr. Glycerol: Production, consumption, prices, characterization and new trends in combustion. Renew. Sustain. Energy Rev. 2013, 27, 475-493. [CrossRef]

20. Oh, P.P.; Lau, H.L.N.; Chen, J.; Chong, M.F.; Choo, Y.M. A review on conventional technologies and emerging process intensification (PI) methods for biodiesel production. Renew. Sustain. Energy Rev. 2012, 16, 5131-5145. [CrossRef]

21. Calero, J.; Luna, D.; Sancho, E.D.; Luna, C.; Bautista, F.M.; Romero, A.A.; Posadillo, A.; Berbel, J.; Verdugo-Escamilla, C. An overview on glycerol-free processes for the production of renewable liquid biofuels, applicable in diesel engines. Renew. Sustain. Energy Rev. 2015, 42, 1437-1452. [CrossRef] 
22. Calero, J.; Luna, D.; Sancho, E.D.; Luna, C.; Posadillo, A.; Bautista, F.M.; Romero, A.A.; Berbel, J.; Verdugo, C. Technological challenges for the production of biodiesel in arid lands. J. Arid Environ. 2014, 102, 127-138. [CrossRef]

23. Verdugo, C.; Luque, R.; Luna, D.; Hidalgo, J.M.; Posadillo, A.; Sancho, E.D.; Rodriguez, S.; Ferreira-Dias, S.; Bautista, F.; Romero, A.A. A comprehensive study of reaction parameters in the enzymatic production of novel biofuels integrating glycerol into their composition. Bioresour. Technol. 2010, 101, 6657-6662. [CrossRef] [PubMed]

24. Luna, C.; Sancho, E.; Luna, D.; Caballero, V.; Calero, J.; Posadillo, A.; Verdugo, C.; Bautista, F.M.; Romero, A.A. Biofuel that keeps glycerol as monoglyceride by 1,3-selective ethanolysis with pig pancreatic lipase covalently immobilized on AlPO4 support. Energies 2013, 6, 3879-3900. [CrossRef]

25. Luna, C.; Verdugo, C.; Sancho, E.D.; Luna, D.; Calero, J.; Posadillo, A.; Bautista, F.M.; Romero, A.A. Production of a biodiesel-like biofuel without glycerol generation, by using Novozym 435, an immobilized Candida antarctica lipase. Bioresour. Bioprocess. 2014, 1, 11. [CrossRef]

26. Luna, C.; Verdugo, C.; Sancho, E.D.; Luna, D.; Calero, J.; Posadillo, A.; Bautista, F.M.; Romero, A.A. Biocatalytic behaviour of immobilized Rhizopus oryzae lipase in the 1,3-selective ethanolysis of sunflower oil to obtain a biofuel similar to biodiesel. Molecules 2014, 19, 11419-11439. [CrossRef] [PubMed]

27. Luna, C.; Luna, D.; Bautista, F.M.; Estevez, R.; Calero, J.; Posadillo, A.; Romero, A.A.; Sancho, E.D. Application of Enzymatic Extracts from a CALB Standard Strain as Biocatalyst within the Context of Conventional Biodiesel Production Optimization. Molecules 2017, 22, 2025. [CrossRef]

28. Calero, J.; Cumplido, G.; Luna, D.; Sancho, E.D.; Luna, C.; Posadillo, A.; Bautista, F.M.; Romero, A.A.; Verdugo-Escamilla, C. Production of a Biofuel that Keeps the Glycerol as a Monoglyceride by Using Supported KF as Heterogeneous Catalyst. Energies 2014, 7, 3764-3780. [CrossRef]

29. Calero, J.; Luna, D.; Sancho, E.D.; Luna, C.; Bautista, F.M.; Romero, A.A.; Posadillo, A.; Verdugo, C. develoment of a new biodiesel that integrates glycerol, by using $\mathrm{CaO}$ as heterogeneous catalyst, in the partial methanolysis of sunflower oil. Fuel 2014, 7, 94-102. [CrossRef]

30. Dias, J.M.; Araújo, J.M.; Costa, J.F.; Alvim-Ferraz, M.C.M.; Almeida, M.F. Biodiesel production from raw castor oil. Energy 2013, 53, 58-69. [CrossRef]

31. Kim, K.H.; Lee, O.K.; Lee, E.Y. Nano-Immobilized Biocatalysts for Biodiesel Production from Renewable and Sustainable Resources. A review. Catalysts 2018, 8, 68. [CrossRef]

32. Bello, E.I.; Makanju, A. Production, Characterization and Evaluation of Castor oil Biodiesel as Alternative Fuel for Diesel Engines. J. Emerg. Trends Eng. Appl. Sci. 2011, 2, 525-530.

33. Scholz, V.; Silva, J.N. Prospects and risks of the use of castor oil as a fuel. A review. Biomass Bioenergy 2008, 32, 95-100. [CrossRef]

34. Patel, V.R.; Dumancas, G.G.; Viswanath, L.C.K.; Maples, R.; Subong, B.J.J. Castor Oil: Properties, Uses, and Optimization of Processing Parameters in Commercial Production. Lipid Insights 2016, 9, 1-12. [CrossRef]

35. Knothe, G. "Designer" Biodiesel: Optimizing Fatty Ester Composition to Improve Fuel Properties. Energy Fuels 2008, 22, 1358-1364. [CrossRef]

36. Berman, P.; Nizri, S.; Wiesman, Z. Castor oil biodiesel and its blends as alternative fuel. Biomass Bioenergy 2011, 35, 2861-2866. [CrossRef]

37. Panwar, N.L.; Shrirame, H.Y.; Rathore, N.S.; Jindal, S.; Kurchania, A.K. Performance evaluation of a diesel engine fueled with methyl ester of castor seed oil. Appl. Therm. Eng. 2010, 30, 245-249. [CrossRef]

38. Valente, O.S.; Silva, M.J.; Pasa, V.M.D.; Belchior, C.R.P.; Sodré, J.R. Fuel consumption and emissions from a diesel power generator fuelled with castor oil and soybean biodiesel. Fuel 2010, 89, 3637-3642. [CrossRef]

39. Nabi, M.N.; Akhter, M.S.; Shahadat, M.M.Z. Improvement of engine emissions with conventional diesel fuel and diesel-biodiesel blends. Bioresour. Technol. 2006, 97, 372-378. [CrossRef]

40. Atabani, A.E.; Silitonga, A.S.; Ong, H.C.; Mahlia, T.M.I.; Masjuki, H.H. Non-edible vegetable oils: A critical evaluation of oil extraction, fatty acid compositions, biodiesel production, characteristics, engine performance and emissions production. Renew. Sustain. Energy Rev. 2013, 18, 211-245. [CrossRef]

41. Gokdogan, O.; Eryilmaz, T.; Yesilyurt, M.K. Thermophysical properties of castor oil (Ricinus communis L.) biodiesel and its blends. CTEF 2015, 6, 95-128.

42. Akanaw, T.T.; Moges, H.G.; Babu, R.; Bisrat, D. Castor Seed from Melkasa Agricultural Research Centre, East Showa, Ethiopia and it's biodiesel performance in Four Stroke Diesel Engine. Int. J. Renew. Energy Dev. 2014, 3, 3-99. [CrossRef] 
43. Mobarak, H.M.; Mohamad, E.N.; Masjuki, H.H.; Kalam, M.A.; Mahmud, K.A.H.A.; Habibullah, M.; Ashraful, A.M. The prospects of biolubricants as alternatives in automotive applications. Renew. Sustain. Energy Rev. 2014, 33, 34-43. [CrossRef]

44. Posadillo, A. ptimization of Experimental Conditions for the Production of Second Generation Biofuels that Integrate Glycerol. Universidad de Córdoba, 2016. Available online: https:/ /helvia.uco.es/handle/10396/ 13237 (accessed on 1 October 2015).

45. Lee, W.J.; Liu, Y.-C.; Mwangi, F.K.; Chen, W.H.; Lin, S.-L.; Fukushima, Y.; Liao, C.-N.; Wang, L.C. Assessment of energy performance and air pollutant emissions in a diesel engine generator fueled with water-containing ethanol-biodiesel-diesel blend of fuels. Energy 2011, 36, 5591-5599. [CrossRef]

46. Chaves, L.I.; de Souza, S.N.M.; Rosa, H.A.; Bariccatti, R.A.; Nogueira, C.E.C.; Secco, D.; Wazilewski, W.T.; Avaci, A.B.; Brenneisen, P.J.; da Silva, M.J. Comparative performance of a diesel cycle engine using blends of diesel and biodiesel. Afr. J. Biotechnol. 2012, 11, 14578-14585. [CrossRef]

47. Blanco, M.; Coello, J.; Maspoch, S.; Puigdomènech, A.; Peralta, X.; González, J.M.; Torres, J. Correlating Bacharach opacity in fuel oil exhaust. prediction of the operating parameters that reduce it. Oil Gas Sci. Technol. IFP 2000, 55, 533-541.

(C) 2019 by the authors. Licensee MDPI, Basel, Switzerland. This article is an open access article distributed under the terms and conditions of the Creative Commons Attribution (CC BY) license (http://creativecommons.org/licenses/by/4.0/). 